\title{
MICROWAVE INVESTIGATION OF MAGNETIC PERMEABILITY OF MANGANITES
}

\author{
K. Repšas, A. Laurinavičius, A.R. Vaškevičius, and F. Anisimovas \\ Semiconductor Physics Institute, A. Goštauto 11, LT-01108 Vilnius, Lithuania \\ E-mail: anis@pfi.lt
}

Received 12 July 2006

\begin{abstract}
The real $\mu^{\prime} / \mu_{0}$ and imaginary $\mu^{\prime \prime} / \mu_{0}$ parts of the relative magnetic permeability of $\mathrm{La}_{0.7} \mathrm{Ca}_{0.3} \mathrm{MnO}_{3}$ thin films and the influence of the electric permittivity and resistivity on the measurement results were investigated under microwave radiation of $10 \mathrm{GHz}$ frequency employing the waveguide measurement and splitter methods.
\end{abstract}

Keywords: manganites thin films, microwave radiation

PACS: 75.47.Lx, 75.47.De, 78.70.Gq

\section{Introduction}

Colossal magnetoresistance in polycrystalline manganites allows one to expect a broad application of these materials in designing new basic elements of information technology. This is the reason of great interest in them nowadays. They are studied employing both DC and microwave current. Nevertheless, in spite of numerous investigations this phenomenon is not completely understood. Apparently, this is so because up to now there are no reliable experimental data on the basic parameters characterizing these materials, such as the real and imaginary parts of electric permittivity and magnetic permeability measured in the microwave frequency range. The work [1] may serve as an example where it has been obtained that, depending on temperatures, in $\mathrm{La}_{0.7} \mathrm{Ca}_{0.3} \mathrm{MnO}_{3}$ thin films the real part $\mu^{\prime} / \mu_{0}$ of relative magnetic permeability may be either positive or negative. This could happen because of neglection of the possible influence of substrate as well as the role of electric permittivity and resistivity of the thin film. Therefore the main goal of the present work was to investigate experimentally the real $\mu^{\prime} / \mu_{0}$ and imaginary $\mu^{\prime \prime} / \mu_{0}$ parts of relative magnetic permeability of the $\mathrm{La}_{0.7} \mathrm{Ca}_{0.3} \mathrm{MnO}_{3}$ thin films using the known method of a waveguide measurement line. Such an aim involved a number of auxiliary tasks. To estimate the influence of electric permittivity and complex conductivity of the $\mathrm{MgO}$ substrate and the conductivity of thin film itself, they had to be additionally measured

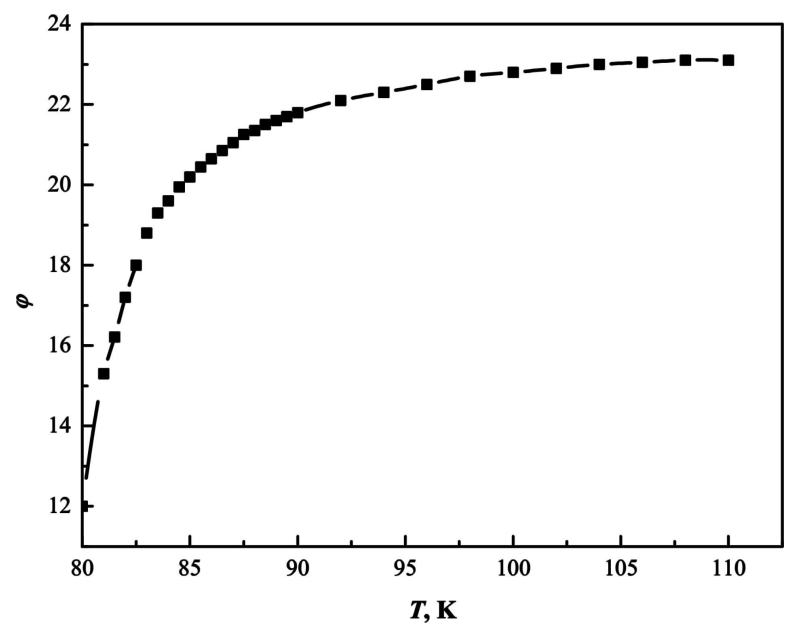

Fig. 1. Dependence of experimentally measured $\varphi$, the phase of a reflected from sample wave, on temperature.

(the conductivity was measured using the wave splitters while measuring the wave absorption by the thin film).

The dependence of phase of reflected wave on temperature $T$ is presented in Fig. 1. It is seen on the graph that at $T>96 \mathrm{~K}$, i.e. when $\mu^{\prime} / \mu_{0} \approx 1$, and $\mu^{\prime \prime} / \mu_{0} \approx$ 0 , the phase of reflected wave $\varphi \approx 22^{\circ}$. Decreasing the temperature the $\varphi$ decreases and $\varphi \approx 12^{\circ}$ at $T \approx 80 \mathrm{~K}$. Such dependence of $\varphi$ on $T$ may be determined by two factors:

(1) dependence of the resistivity on $T$,

(2) manifestation of the complex magnetic permeability $\mu$ at low temperatures. 
So, it is necessary to solve the indicated additional tasks.

\section{Estimating the possibilities to measure the electric permittivity, magnetic permeability, and resistivity of granules}

As the thickness of substrate with the investigated thin film is much smaller than the wavelength in the waveguide, we make an assumption that the strength of electric field in the substrate and the thin film is the same, but the currents in those are different and determined by their complex conductivities. Then their common conductivity should be like this:

$$
\frac{1}{Z}=\frac{1}{Z_{\mathrm{f}}}+\frac{1}{Z_{\mathrm{s}}},
$$

here $1 / Z_{\mathrm{f}}$ and $1 / Z_{\mathrm{s}}$ are the thin film and the substrate conductivities. Then the thin film complex conductivity may be written down as follows:

$$
\frac{1}{Z_{\mathrm{f}}}=\sqrt{\left(\frac{1}{R_{\mathrm{f}}}\right)^{2}+\left(\frac{1}{X_{\mathrm{f}}}\right)^{2}} \mathrm{e}^{-\mathrm{i} \varphi_{\mathrm{f}}}=\sqrt{\frac{\varepsilon_{a}^{\prime}-\mathrm{i} \varepsilon_{a}^{\prime \prime}}{\mu_{a}^{\prime}-\mathrm{i} \mu_{a}^{\prime \prime}}},
$$

here $1 / R_{\mathrm{f}}=1 / R-1 / R_{\mathrm{s}}, 1 / X_{\mathrm{f}}=1 / X-1 / X_{\mathrm{s}}$, and $\varphi_{\mathrm{f}}=\varphi-\varphi_{\mathrm{s}}$, with $1 / R_{\mathrm{f}}, 1 / X_{\mathrm{f}}$ being real and imaginary parts of the thin film complex conductivity, expressed via the difference of total $1 / R$ and substrate $1 / R_{\mathrm{S}}$ complex conductivity parts, and $\varphi_{\mathrm{f}}$ is the angle between current and voltage in the thin film.

Rearranging this equation we obtain the following real and imaginary parts of the thin film complex conductivity:

$$
\begin{aligned}
& {\left[\left(\frac{1}{R_{\mathrm{f}}}\right)^{2}+\left(\frac{1}{X_{\mathrm{f}}}\right)^{2}\right] \cos 2 \varphi_{\mathrm{f}}=\frac{\varepsilon_{a}^{\prime}}{\mu_{a}^{\prime}} \frac{1+\frac{\varepsilon_{a}^{\prime \prime}}{\varepsilon_{a}^{\prime}} \frac{\mu_{a}^{\prime \prime}}{\mu_{a}^{\prime}}}{1+\left(\frac{\mu_{a}^{\prime \prime}}{\mu_{a}^{\prime}}\right)^{2}},} \\
& {\left[\left(\frac{1}{R_{\mathrm{f}}}\right)^{2}+\left(\frac{1}{X_{\mathrm{f}}}\right)^{2}\right] \sin 2 \varphi_{\mathrm{f}}=\frac{\varepsilon_{a}^{\prime}}{\mu_{a}^{\prime}} \frac{\frac{\varepsilon_{a}^{\prime \prime}}{\varepsilon_{a}^{\prime}}-\frac{\mu_{a}^{\prime \prime}}{\mu_{a}^{\prime}}}{1+\left(\frac{\mu_{a}^{\prime \prime}}{\mu_{a}^{\prime}}\right)^{2}} .}
\end{aligned}
$$

By selecting such a temperature $T_{1}$ that $\mu_{a}^{\prime \prime}=0$ and $\mu_{a}^{\prime}=\mu_{0}$, we then obtain from the real part (3) that the relative electric permittivity is

$$
\varepsilon_{\mathrm{f}}=\frac{\mu_{0}}{\varepsilon_{0}}\left[\left(\frac{1}{R_{\mathrm{f}}}\right)^{2}+\left(\frac{1}{X_{\mathrm{f}}}\right)^{2}\right] \cos 2 \varphi_{\mathrm{f}},
$$

and from the imaginary part (4)

$$
\varepsilon_{a}^{\prime \prime}\left(T_{1}\right)=\mu_{0}\left[\left(\frac{1}{R_{\mathrm{f}}}\right)^{2}+\left(\frac{1}{X_{\mathrm{f}}}\right)^{2}\right] \sin 2 \varphi_{\mathrm{f}} .
$$

As the imaginary electric permittivity $\varepsilon_{a}^{\prime \prime}$ depends on the conductivity of thin film granules, the obtained result is valid just for a single temperature $T=T_{1}$. It is possible to extend the limits of application of this result if we measured the dependence of thin film granule resistivity on temperature.

By dividing the imaginary part (4) by the real one (3), we obtain that

$$
\tan 2 \varphi_{\mathrm{f}}=\frac{\frac{\varepsilon_{a}^{\prime \prime}}{\varepsilon_{a}^{\prime}}-\frac{\mu_{a}^{\prime \prime}}{\mu_{a}^{\prime}}}{1+\frac{\varepsilon_{a}^{\prime \prime}}{\varepsilon_{a}^{\prime}} \frac{\mu_{a}^{\prime \prime}}{\mu_{a}^{\prime}}} .
$$

The quantity $\mu_{a}^{\prime \prime} / \mu_{a}^{\prime}$ may be found from such an equation. By substituting that into the real part of the complex conductivity of the thin film we may obtain the quantity $\mu_{a}^{\prime}$ and its temperature dependence.

In determining the complex magnetic permeability the knowledge of dependence of the resistivity of granules on temperature is necessary. Therefore we shall look into possibilities to measure it by employing the wave absorption, assuming that the wave electric field in the thin film is evoked by the power of its incoming wave, i. e. by the quantity

$$
\frac{P_{\mathrm{abs}}\left(T_{0}\right)}{P_{\mathrm{abs}}(T)}=\frac{\sigma\left(T_{0}\right)\left(1-\frac{P_{\mathrm{ref}}\left(T_{0}\right)}{P_{\mathrm{i}}\left(T_{0}\right)}\right) \cos \varphi_{\mathrm{f}}\left(T_{0}\right)}{\sigma(T)\left(1-\frac{P_{\mathrm{ref}}(T)}{P_{\mathrm{i}}(T)}\right) \cos \varphi_{\mathrm{f}}(T)},
$$

here $\sigma$ is the conductivity of a thin film and $P_{\text {abs }}$ is the power absorbed by the thin films.

Let us assume that in Eq. (8) $\left[1-P_{\text {ref }}\left(T_{0}\right) / P_{\mathrm{i}}\left(T_{0}\right)\right] \approx$ $\left[1-P_{\text {ref }}(T) / P_{\mathrm{i}}(T)\right]$, i.e. the temperature dependence of absorbed powers is determined only by the temperature-dependent conductivities and angles.

We get from Eq. (8) that

$$
\frac{\rho(T)}{\rho\left(T_{0}\right)} \approx \frac{\frac{P_{\mathrm{abs}}\left(T_{0}\right) \cos \varphi_{\mathrm{f}}(T)}{P_{\mathrm{i}}\left(T_{0}\right) \cos \varphi_{\mathrm{f}}\left(T_{0}\right)}}{\frac{P_{\mathrm{abs}}(T)}{P_{\mathrm{i}}(T)}} .
$$

Thus, after measuring the relative absorbed powers of the wave, as well as $\cos \varphi_{\mathrm{f}}$ at temperatures $T_{0}$ and $T$, one may obtain the dependence of relative resistivity of granules, and so the same of complex magnetic permeability, on temperature $T$. 


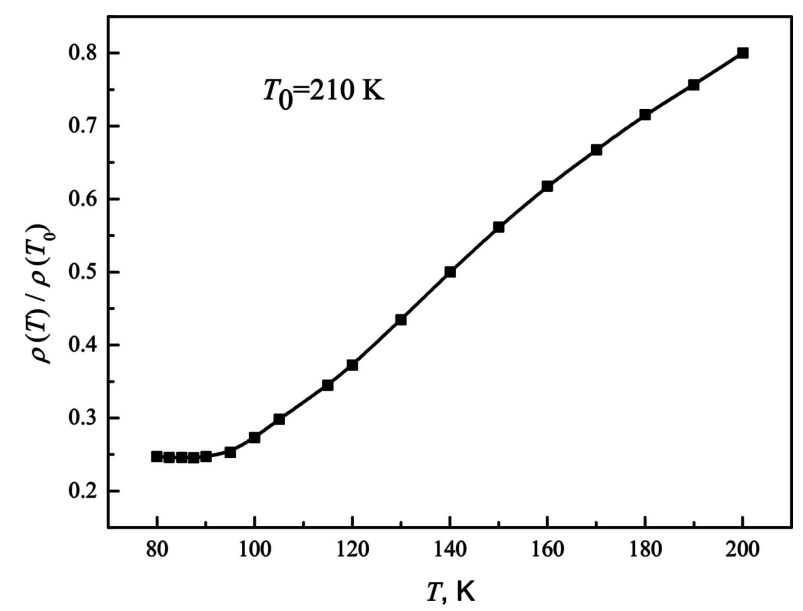

Fig. 2. Dependence of granule relative resistivity $\rho(T) / \rho\left(T_{0}\right)$ on temperature $T$.

\section{Experimental approach}

Granulary $\mathrm{La}_{0.67} \mathrm{Ca}_{0.33} \mathrm{MnO}_{3}$ films were fabricated by laser evaporation using a ceramic target of the same composition, on the $0.7 \mathrm{~mm}$ thick $\mathrm{MgO}$ substrates having the temperature up to $750{ }^{\circ} \mathrm{C}$. The evaporation was performed at oxygen pressure of 20-25 $\mathrm{Pa}$. After evaporation its pressure was increased up to $10^{5} \mathrm{~Pa}$, then the substrate temperature was gradually decreased down to the room temperature. Deposited $0.2 \mu \mathrm{m}$ thick thin films had conventional dependence on temperature and magnetic field. The temperature of the top of a peak was $T_{\mathrm{m}} \approx 150 \mathrm{~K}$. Microwave measurements were carried out in the $10 \mathrm{GHz}$ frequency range. The power of waves in use did not exceed $1 \mathrm{~mW}$, for the sensors to operate in the linear part of their volt-watt characteristics. The thin film with substrate covered the whole window of a waveguide head. Complex electric permittivities and magnetic permeabilities were measured using the waveguide measurement method, and the resistivity of granules by measuring the absorbed power of the wave employing the splitters.

\section{Results and discussion}

The dependence of reflected wave phase $\varphi$ upon temperature $T$ is plotted in Fig. 1, and the relative resistivity $\rho(T) / \rho\left(T_{0}\right)$ versus temperature $T$ in Fig. 2. While comparing those two curves it is easy to notice that in the regions where abrupt changes of phase $\varphi$ versus $T$ occur the relative resistivity of granules $\rho(T) / \rho\left(T_{0}\right)$ is changing only slightly and vice versa, where the phase $\varphi$ changes slowly with $T$, there the relative resistivity of granules $\rho(T) / \rho\left(T_{0}\right)$ is changing with $T$ much faster. This indicates that the fast

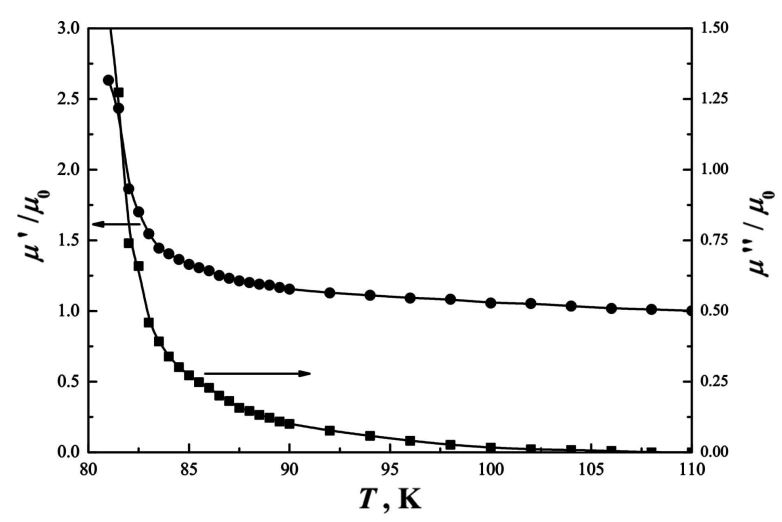

Fig. 3. Dependence of real $\mu^{\prime} / \mu_{0}$ and imaginary $\mu^{\prime \prime} / \mu_{0}$ parts of a complex relative magnetic permeability of granules on temperature $T$.

change of phase $\varphi$ with $T$ is almost unrelated to the change of relative resistivity of granules $\rho(T) / \rho\left(T_{0}\right)$. And on the opposite, the slow change of $\varphi$ is apparently determined by the $\rho(T) / \rho\left(T_{0}\right)$ change with $T$. The fact that the fast change of phase $\varphi$ with $T$ is determined not by the dependence of granule resistivity on $T$, but rather by the relative magnetic permeabilities $\mu^{\prime} / \mu_{0}$ and $\mu^{\prime \prime} / \mu_{0}$ depending upon $T$, is confirmed by Fig. 3. There the dependence of theses quantities on $T$ is shown. Their fastest changes with $T$ are observed in the same temperature interval where the $\varphi$ changes with temperature are the fastest.

In solving the auxiliary tasks the following results have been obtained:

1. The real and the imaginary parts of complex conductivity of the $\mathrm{MgO}$ substrate have been measured and the value $\varepsilon_{\mathrm{s}} \approx 10$ of its relative electric permittivity has been found that well agrees with the value $\varepsilon_{\mathrm{s}} \approx 10$ given in the literature [2].

2. The measurement of relative electric permittivity of the thin film, $\varepsilon_{\mathrm{f}}=4.5$, has been a success for the first time.

3. Dependence of the relative resistivity of granules, $\rho(T) / \rho\left(T_{0}\right)$, on temperature has been measured and its absolute value $\rho=0.4 \Omega \mathrm{m}$ at room temperature has been obtained.

\section{Conclusion}

Microwave investigation of magnetic permeability of manganite granules is rather complex, involving almost every parameter characteristic of manganites, such as the real and imaginary parts of a complex electric permittivity and the resistivity of granules. 


\section{References}

[1] N.J. Solin, S.V. Naumov, and A.A. Samokhvalov, Interface phenomena and microwave magnetoresistivity in policrystalline $\mathrm{La}_{1-x} \mathrm{Ca}_{x} \mathrm{MnO}_{3}$ lanthanum manganites, Fiz. Tverd. Tela (St. Petersburg) [Phys. Solid State] 42, 899-904 (2000) [in Russian].

[2] E.K. Hollman, O.G. Vendik, A.G. Zaitsev, and
B.T. Melekh, Substrates for high- $T_{\mathrm{c}}$ superconductor microwave integrated cirtuits, Supercond. Sci. Technol. 7, 609-622 (1994).

[3] A. Lučun, F. Anisimovas, O. Kiprijanovič, A. Maneikis, Ž. Kavaliauskas, J. Gradauskas, A. Sužiedèlis, B. Vengalis, and S. Ašmontas, Investigation of polycrystalline LCMO films by strong microwave and DC electric fields, Lithuanian J. Phys. 46, 245-249 (2006).

\section{MIKROBANGIS MANGANITU MAGNETINĖS SKVARBOS TYRIMAS}

K. Repšas, A. Laurinavičius, A.R. Vaškevičius, F. Anisimovas

Puslaidininkiu fizikos institutas, Vilnius, Lietuva

\section{Santrauka}

Naudojantis žinomais bangolaidinès matavimo linijos ir atšakotuvų metodais eksperimentiškai ištirtos $\mathrm{La}_{0,67} \mathrm{Ca}_{0,33} \mathrm{MnO}_{3}$ sluoks- nių realioji $\mu^{\prime} / \mu_{0}$ ir menamoji $\mu^{\prime \prime} / \mu_{0}$ magnetinès skvarbos dalys, ¿̨skaitant $\mathrm{MgO}$ padéklo bei sluoksnio dielektrinès skvarbos ir granulių savitosios varžos įtaką matavimų rezultatams. 